\title{
Penile prosthesis, sexual satisfaction and representation of male erotic value
}

\author{
PHILIPPE KEMPENEERS ${ }^{1,2}$, ROBERT ANDRIANNE $^{3}$ \& \\ CHRISTIAN MORMONT ${ }^{1}$ \\ ${ }^{1}$ Department of Clinical Psychology, University of Liege. Bd du Rectorat, B33, 4000 \\ Liège, Belgium, 'Alexians' Hospital. Ruyff, 68, 4841 Henri-Chapelle, Belgium, \\ ${ }^{3}$ Department of Urology, University of Liege. CHU de Liège, Domaine du Sart Tilman, \\ B35, 4000 Liège, Belgium
}

\begin{abstract}
A follow-up study conducted among 39 implanted patients and 30 partners shows that subject's satisfaction towards prosthetic-sexuality depends on their representation of male erotic value. The less satisfied patients are sensitive to a normative representation that associates erotic value to criteria of 'spontaneity', 'naturalness', 'tall and non-assisted erections'. Their main dissatisfaction likely derives from the insufficiency of a prosthetic solution to restore a male self-image based on such criteria. This induces a more important impact on satisfaction rates than do functional problems (e.g. difficulties in manipulating the device, unwanted deflations, uncomfortable sensations). These patients also show an attribution bias consisting in attributing erroneously the same dissatisfaction and negative attitude towards prosthetic sexuality to their partner. Therefore, in addition to surgery, a psychosexual support is necessary to modify erotic representations and to improve the communication between the partners in order to increase sexual satisfaction with prosthesis-assisted sexuality.
\end{abstract}

KEYWORDS: penile prosthesis; sexual satisfaction; social representation; erectile disorder; couple; virility; sexual communication.

\section{Introduction}

Among the treatments of erectile disorders, the implantation of a penile prosthesis is a last option reserved for cases of severe erectile dysfunctions due to an organic etiology.

The follow-up surveys conducted among penile prosthesis users generally report excellent satisfaction rates (Holloway \& Farah, 1997; Kupeli et al., 1999; Montorsi et al., 2000). However, if the implanted patients are often very satisfied, the satisfaction is not maximal in all cases.

Correspondence to: Phillippe Kempeneers, Service de Psychologie Clinique, Université de Liège, Bd. du Rectorat, B33, B-4000 Liège, Belgium. Tél.: (32)87/59.32.11; Fax: (32)87/88.27.38;

E-mail: p.kempeneers@belgacom.net

Received 28 February 2004; Accepted 15 June 2004. 
Several factors may induce a decrease in the satisfaction rates:

(1) Firstly, postoperative complications (e.g. device malfunction, erosion, infection) may occur and burden patients' satisfaction (Goldstein et al., 1993; Holloway \& Farah, 1997). Fortunately, most of these problems are remediable (Mulcahy, 2000).

(2) Secondly, functional difficulties can alter satisfaction. Indeed, it is not always easy to use the prosthetic device correctly; some pain may be experienced during the first intercourses, as well as sensations of discomfort during urination or to the contact of clothing; some patients also complain about a lack of penile sensitivity (Kempeneers, et al., 1992; McLaren \& Barrett, 1992). Patients are then disappointed by such difficulties, and their satisfaction is diminished. However, several studies suggest that these problems are transient, they tend to fade gradually either spontaneously or through an adaptation process to the new aspects of the implanted penis. In consequence, follow-up studies report that the satisfaction levels frequently improve with time (Anafarta et al., 1998; Kempeneers et al., 1992; Tefilli et al., 1998).

(3) Thirdly, the satisfaction of prosthesis-assisted sexuality may be altered by psychological and relational factors. Several studies indicate that the least satisfaction was found in patients who are the most aware of the 'unnatural' aspect of the prosthesis (Montorsi et al., 2000; Porena et al., 1999). In the same way, Collins and Kinder (1984) and Schover and Von Eschenbach (1985) argue that low satisfaction is characteristic of couples with important conflicts or with sexual desire troubles. Such considerations emphasise the relevance of psychosexual counselling in addition to surgical approach (Schover, 1989).

Compared to the studies on the technical and material aspects of the prosthetic surgery, those assessing the psychological components of the patients' adjustment to prosthesis-assisted sexuality are rather limited. The aim of the present study is to add some elements to the understanding of these psychological factors. More precisely, the study needs to investigate how a specific social representation of erotic value plays a role in couples' dissatisfaction at prosthesis-assisted sexuality.

According to Moscovici $(1981,1988)$, the concept of social representation refers to a socially induced perception of an object and it is defined by an attribution of meaning that governs the attitude towards this object. It is reasonable to expect that, depending on their contents, the social representations of sexuality can influence the satisfaction with prosthesis-assisted sexuality in a positive or negative way. Previous studies by our team suggested that the less satisfied patients were those males who felt diminished, associated the prosthesis to ideas of 'artificial virility' and complained about erections not being large enough (Kempeneers et al., 1992, 1994a). These observations indicated that a specific representation of male erotic value was concerned in the explanation of dissatisfaction. The purpose of the present study is to assess more precisely the dynamic of such a representation. 
Everybody has his own representation of what is 'good sexuality'. Following individuals or groups, representations of sexuality may be more or less narrow, normative and rigid. From a general point of view, sexual dissatisfaction frequently results from a discrepancy between, on the one hand, a certain representation of 'good' sexuality and, on the other hand, the actual functioning of the body. Schematically, the aim of clinical interventions is to reduce this discrepancy by using both medical or behavioural strategies (e.g. drugs, surgery, purely behavioural techniques), in order to improve the body's functioning, and cognitive and emotional approaches in order to make some representations more adequate (e.g. psychosexual counselling). In the present study, we hypothesize that, in some cases, surgery alone may be insufficient to restore sexual satisfaction since patient's representation of sexuality is recalcitrant to fit with a penile implant, this representation calling for a further psychosexual intervention in order to adjust it to the actual prostheticfunctioning of the body and also to improve the satisfaction.

\section{Method and population}

Thirty-nine implanted patients have completed a survey questionnaire. The total number of patients implanted in the University Hospital of Liege (Belgium) during this period was 69 , but some patients were excluded from the target population: patients with unresolved mechanical or medical problems $(n=2)$, patients who could not be localized for the study (changing address, $n=6$ ), and patients who died in the meantime $(n=3)$. Finally, on the 58 remaining patients, the participation rate was of $67 \%$.

All the patients received a three-piece AMS prosthesis (Ultrex:87\%; 700 CX: $13 \%)$.

No differences were found between participants and non-participants concerning the age, the model implanted and the time lapse since prosthesis implantation.

The follow-up questionnaire explored the following parameters:

- Satisfaction with prosthesis-assisted sexuality,

- Satisfaction attributed to the partner concerning prosthesis-assisted sexuality,

- Feelings of shame derived from having a penile prosthesis,

- Tendency to consider the prosthesis as a handicap in their sexual and relational life,

- Frequency and/or importance of functional problems like difficulties in manipulating the device, unwanted deflations, pains, uncomfortable sensations and lack of penile sensitivity after implantation,

- Satisfaction about the length of the penis after implantation.

These parameters were measured by multi-point scales (e.g. $1=$ 'not satisfied at all', 'never', 'not important at all' $->5=$ 'entirely satisfied', 'always', 'very important').

Two original multi-item scales were also inserted in the questionnaire :

- The first one aimed to assess the patients' Attitude towards Penile Implant (the API scale, described in Table I). The API scale was built on Likert's (1932) 
API scale: Attitude towards Penile Implant (adapted from French)

1 The prosthesis makes sexual intercourse artificial $\left(0.69 ; p<0.0001^{\circ}\right)$

2 Activating the prosthesis disrupts sexual activities $\left(0.75 ; p<0.0001^{\circ}\right)$

3 Penile prosthesis is a 'plastic virility' $\left(0.72 ; p<0.0001^{\circ}\right)$

4 The prosthesis damages the charm of sexual activities $\left(0.79 ; p<0.0001^{\circ}\right)$

$5^{\star}$ Whether the erection is prosthetic or natural does not matter, as long as there is an erection $(0.56$; $\left.p<0.0001^{\circ}\right)$

6 With a prosthesis, sexual intercourse cannot be said to be 'normal' $\left(0.80 ; p<0.0001^{\circ}\right)$

7 Activating the prosthesis may be awkward for a man in sexual meeting with a new partner $(0.49$; $\left.p<0.0001^{\circ}\right)$

8 Having a penile prosthesis is shameful for a man $\left(0.82 ; p<0.0001^{\circ}\right)$

Each of the 8 proposals matches a six-point scale by which the subject indicates his degree of agreement:

\begin{tabular}{lccccc}
\hline 1 & 2 & 3 & 4 & 5 & 6 \\
$\begin{array}{l}\text { strongly } \\
\text { false }\end{array}$ & $\begin{array}{c}\text { rather } \\
\text { false }\end{array}$ & $\begin{array}{c}\text { more false } \\
\text { than true }\end{array}$ & $\begin{array}{c}\text { more true } \\
\text { than false }\end{array}$ & $\begin{array}{c}\text { rather } \\
\text { true }\end{array}$ & $\begin{array}{c}\text { strongly } \\
\text { true }\end{array}$ \\
\hline
\end{tabular}

$\left.{ }^{\circ}\right)$ Spearman correlation test: individual item/total scale

Recording of the subjects' answers

The Attitude towards Penile Implant is expressed by a score whose high value express an unfavourable attitude while its low values express a favourable attitude. Its calculation is obtained as follows: The item 5 , marked by an asterisk $\left({ }^{\star}\right)$, is a statement favourable to the penile implant. The examiner has to reverse the note of agreement provided by the subject so that value 1 expresses the most favourable extreme and value 6 the most unfavourable extreme. The other items correspond to unfavourable proposals: the notes are recorded as provided by the subject. The total score corresponds to the sum of the notes thus recorded. It can vary from 8 (most favourable attitude towards penile implant) to 48 points (most unfavourable attitude towards penile implant).

model. The attitude score is the sum of several opinions about prosthesisassisted sexuality. The high values correspond to a negative attitude towards penile implant, they refer to something like a concept of 'prosthetic virility', an injured self-image, an impression of self-erotic value damaged by ideas such 'assistance', 'lack of spontaneity' and 'lack of naturalness' associated to penile prosthesis.

- The second original multi-item scale aimed to assess the attitude towards penile implant as projected by the patient in his partner's mind; it is named Attitude Attributed to the Partner towards Penile Implant (AAPPI scale, see Table II) and is built on the same model as the API scale.

Thirty partners have also completed a similar questionnaire which explored:

- Their satisfaction with prosthesis-assisted sexuality and

- Their actual attitude towards penile implant. This last parameter was assessed by a scale named Partner's Attitude towards Penile Implant (PAPI scale, see Table III) and was built on the same model as the API scale. 
AAPPI scale: Attitude Attributed to the Partner towards Penile Implant (adapted from French)

1 If the erection is due to a prosthesis, my partner cannot measure either my sexual desire or my arousal $\left(0.62 ; p<0.001^{\circ}\right)$

2 A priori, my partner is not willing to have sexual intercourse with a man having a penile prosthesis $\left(0.66 ; p<0.001^{\circ}\right)$

3 My partner considers the penile implant mainly as a means to please me since she does not enjoy prothesis-assisted sex $\left(0.72 ; p<0.002^{\circ}\right)$

$4^{\star}$ My partner thinks that the penile prothesis is a good means to express my virility $\left(0.56 ; p<0.001^{\circ}\right)$

5 Since the implantation, my partner is more hesitant to touch my penis $\left(0.68 ; p<0.0001^{\circ}\right)$

$6^{\star}$ Since the implantation, my partner feels more desirable $\left(0.49 ; p<0.007^{\circ}\right)$

$\left({ }^{\circ}\right)$ Spearman correlation test: individual items/total scale.

The methods of answer and recording are similar to those of API. The total score can vary here from 6 (most favourable attitude towards penile implant) to 36 points (most unfavourable attitude towards penile implant).

TABLE III PAPI scale

PAPI scale: Partner's Attitude towards Penile Implant (adapted from French)

1 The prosthesis makes sexual intercourse artificial $\left(0.88 ; p<0.0001^{\circ}\right)$

2 Activating the prosthesis disrupts sexual activities $\left(0.80 ; p<0.0001^{\circ}\right)$

3 Penile prosthesis is a 'plastic virility' $\left(0.88 ; p<0.0001^{\circ}\right)$

4 The prosthesis damages the charm of sexual activities $\left(0.81 ; p<0.0001^{\circ}\right)$

$5^{\star}$ Whether the erection is prosthetic or natural does not matter, as long as there is an erection $(0.85$; $p<0.0001^{\circ}$ )

6 With a prosthesis, sexual intercourse cannot be said to be 'normal' $\left(0.82 ; p<0.0001^{\circ}\right)$

7 The simple thought of a foreign body in my vagina decreases my sexual desire and arousal $(0.60$; $p<0.001^{\circ}$ )

8 For me, having a partner with erection problems is still better than having sexual intercourse with a penile prosthesis $\left(0.68 ; p<0.0001^{\circ}\right)$

9 If the erection is due to a prosthesis, I can measure neither my partner's sexual desire nor his arousal $\left(0.65 ; p<0.001^{\circ}\right)$

10 A priori, I am not willing to have sexual intercourse with a man having a penile prosthesis $(0.57$; $p<0.002^{\circ}$ )

( ${ }^{\circ}$ Spearman correlation test: individual item/total scale.

The methods of answer and recording are similar to those of API. The total score can very here from 10 (most favourable attitutde towards penile implant) to 60 points (most unfavourable attitude towards penile implant).

Both men and women also completed the Sexual Irrationality Questionnaire (SIQ, McCormick and Jordan, 1986; French adaptation by Kempeneers et al., 2000). The SIQ intends to assess some dysfunctional beliefs related to sexuality that are assumed to involve sexual difficulties. In the present study, the purpose was therefore to appreciate their impact on the satisfaction with prosthesis-assisted sexuality. In its French version, the factor analysis of the SIQ leads to four subscales corresponding to 


\section{Philippe Kempeneers et al.}

four different fields of maladaptive sexual beliefs: $S I Q-F 1$ (Need for control) refers to an excessive need to keep sexuality, sexual reactions and desires under control; SIQF2 (Lack of communication) refers to a lack of communication in order to adapt sexual activities to the partners' differences in erotic sensitivity; SIQ-F3 (Fantasies) express a tendency to consider certain erotic fantasies as unbecoming; SIQ-F4 (Intolerance to frustration) refers to a lack of tolerance towards sexual frustrations. (Psychometric details reported in Kempeneers et al., 2000).

Data of age, educational level and time lapse since implantation were also taken into account.

The relations between these different parameters were assessed by Spearman correlation coefficients and Student $t$-tests. Firstly, the satisfaction rates towards prosthesis-assisted sexuality (dependent variables) were crossed with each other variable (presumed to be determinant) both for males and females. Secondly, the interrelations between the determinant variables were examined in order to lighten their dynamics.

At the moment of the penile implantation, the patients' age varied from 32 to 71 years (mean 58) and the partners' from 25 to 69 years (mean 49). The follow-up duration was 2 months to 6 years (mean 52 months).

\section{Results}

Figure 1 shows that $67.5 \%$ of the patients and $48.2 \%$ of the partners are entirely satisfied with their prosthesis-assisted sexuality. On the other hand, $10.8 \%$ of men and $11.1 \%$ of women are at most slightly satisfied and $24.3 \%(\mathrm{M})$ and $26 \%(\mathrm{~W})$ are at most moderately satisfied. This surely reflects a kind of loss of therapeutic profit.

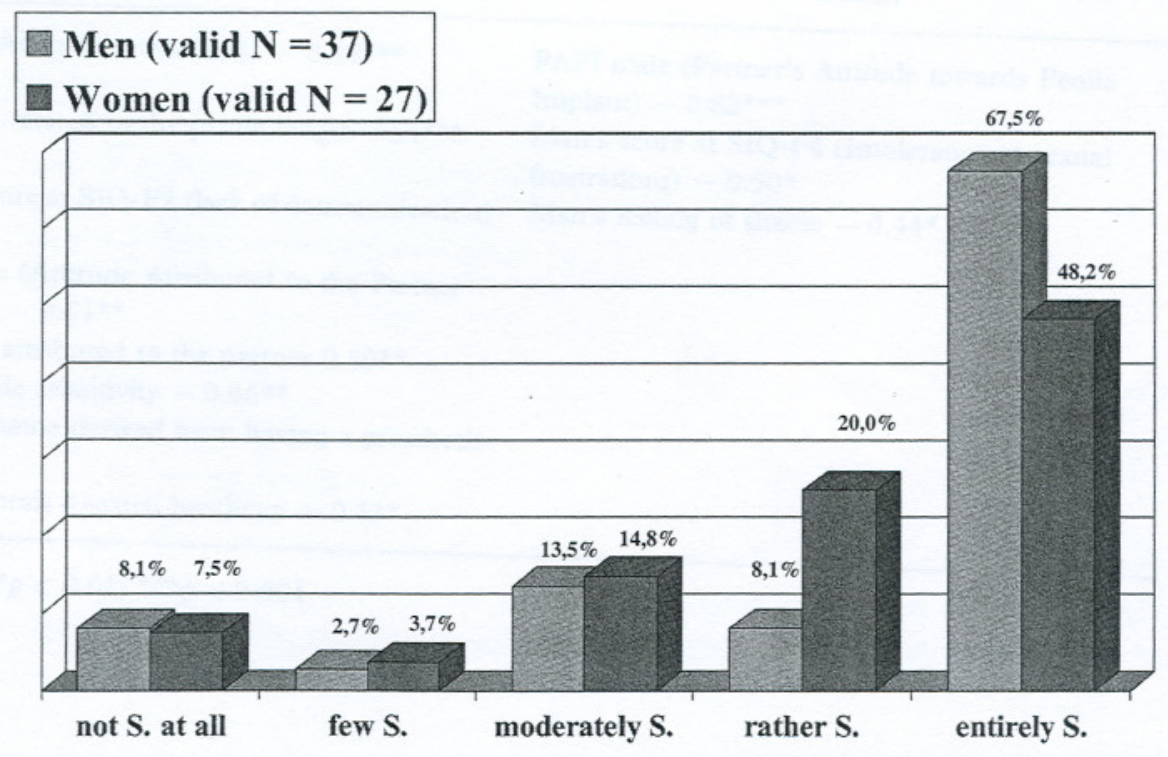


four different fields of maladaptive sexual beliefs: SIQ-F1 (Need for control) refers to an excessive need to keep sexuality, sexual reactions and desires under control; SIQF2 (Lack of communication) refers to a lack of communication in order to adapt sexual activities to the partners' differences in erotic sensitivity; SIQ-F3 (Fantasies) express a tendency to consider certain erotic fantasies as unbecoming; SIQ-F4 (Intolerance to frustration) refers to a lack of tolerance towards sexual frustrations. (Psychometric details reported in Kempeneers et al., 2000).

Data of age, educational level and time lapse since implantation were also taken into account.

The relations between these different parameters were assessed by Spearman correlation coefficients and Student $t$-tests. Firstly, the satisfaction rates towards prosthesis-assisted sexuality (dependent variables) were crossed with each other variable (presumed to be determinant) both for males and females. Secondly, the interrelations between the determinant variables were examined in order to lighten their dynamics.

At the moment of the penile implantation, the patients' age varied from 32 to 71 years (mean 58) and the partners' from 25 to 69 years (mean 49). The follow-up duration was 2 months to 6 years (mean 52 months).

\section{Results}

Figure 1 shows that $67.5 \%$ of the patients and $48.2 \%$ of the partners are entirely satisfied with their prosthesis-assisted sexuality. On the other hand, $10.8 \%$ of men and $11.1 \%$ of women are at most slightly satisfied and $24.3 \%(\mathrm{M})$ and $26 \%(\mathrm{~W})$ are at most moderately satisfied. This surely reflects a kind of loss of therapeutic profit.

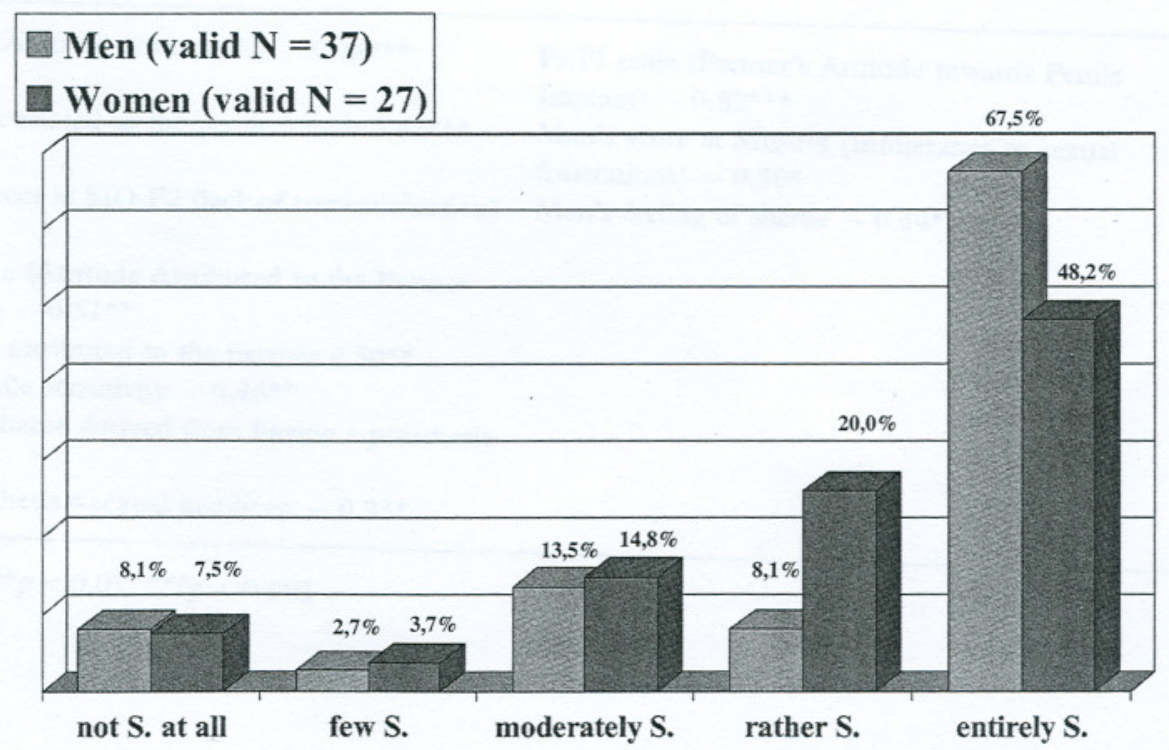

FIG. 1. Relationships between sexual functioning, representation of erotic value, sexual dissatisfaction and interventions. 
Table IV shows that, among men, satisfaction correlates negatively with the API scale, with the women's SIQ-F2 score, with the AAPPI scale, with a lack of penile sensitivity, with a feeling of shame derived from having a penile prosthesis and with a tendency to consider the prosthesis as a sexual handicap, and it correlates positively with the satisfaction related to the penis length and with the satisfaction attributed to the partner. Among women, satisfaction correlates negatively with the PAPI scale, with the men's SIQ-F4 scores and with the men's feeling of shame.

No significant relationships are found either between men's and women's satisfaction, nor between satisfaction rates and criteria of age time lapse since the implantation and educational level.

Except the complaints about diminished penile sensitivity, the functional problems do not have a significant influence on satisfaction rates.

The variables expressing a negative perception of prosthetic sexuality (API, feelings of shame, prosthesis =handicap, PAPI) are of interest to explain the dissatisfaction.

Table V shows that, in the male population, the API scores, the feeling of shame, the fact to consider the prosthesis as a sexual handicap and the disappointment about the penis length are interrelated. This outlines a representation that characterizes the male erotic value by criteria of 'naturalness', 'spontaneity', 'non-assistance' and 'large erections'. Some men's satisfaction and self-image are altered insofar as prosthesisassisted sexuality does not permit to meet such normative criteria.

Table VI shows that the presence in men of such a representation involves a tendency to attribute a negative attitude towards penile implant (AAPPI) and a low satisfaction (SAP) to their partner, while men's attributions are not correlated with the partner's actual attitude (PAPI) and satisfaction.

TABLE IV Variables linked to satisfaction rates

\begin{tabular}{|c|c|}
\hline Men & Women \\
\hline API scale (Attitude towards PI) $-0.74^{\star \star \star}$ & $\begin{array}{l}\text { PAPI scale (Partner's Attitude towards Penile } \\
\text { Implant) }-0.82^{\star \star \star}\end{array}$ \\
\hline Satisfaction related to the penile length $0.64^{\star \star \star}$ & $\begin{array}{l}\text { Man's score at SIQ-F4 (Intolerance to sexual } \\
\text { frustrations) }-0.50^{\star}\end{array}$ \\
\hline $\begin{array}{l}\text { Partner's score at SIQ-F2 (lack of communication) } \\
-0.54^{\star \star}\end{array}$ & Man's feeling of shame $-0.44^{\star}$ \\
\hline $\begin{array}{l}\text { AAPPI scale (Attitude Attributed to the Partner } \\
\text { towards PI) }-0.51^{\star \star}\end{array}$ & \\
\hline Satisfaction attributed to the partner $0.50^{\star \star}$ & \\
\hline Lack of penile sensitivity $-0.46^{\star \star}$ & \\
\hline $\begin{array}{l}\text { Feeling of shame derived from having a prosthesis } \\
-0.41^{\star \star}\end{array}$ & \\
\hline Penile prosthesis $=$ sexual handicap $-0.33^{\star}$ & \\
\hline
\end{tabular}

${ }^{\star} p<0.05 ;{ }^{\star \star} p<0.01 ;{ }^{\star \star \star} p<0.001$ 
TABLE V Interrelations between psychological variables

\begin{tabular}{lrrrr}
\hline & $\mathrm{A}$ & $\mathrm{B}$ & $\mathrm{C}$ & $\mathrm{D}$ \\
\hline $\mathrm{A}$ & & & & \\
$\mathrm{B}$ & $0.44^{\star \star}$ & & & \\
$\mathrm{C}$ & $0.53^{\star \star}$ & $0.55^{\star \star \star}$ & & \\
$\mathrm{D}$ & $-0.60^{\star \star}$ & $-0.38^{\star}$ & $-0.32^{\star \star}$ & \\
\hline
\end{tabular}

${ }^{\star} p<0.05 ;{ }^{\star \star} p<0.01 ;{ }^{\star \star \star} p<0.001$
A: API (Attitude towards Penile Implant)
$\mathrm{B}$ : feeling of shame derived from having a prosthesis
C: prosthesis $=$ sexual handicap
D: satisfaction related to the penile size

Table VI Attitude and satisfaction attributed by the man to his partner and partner's actual attitude and satisfaction

\begin{tabular}{|c|c|c|c|c|}
\hline & \multicolumn{2}{|c|}{ Man's attribution } & \multicolumn{2}{|c|}{$\begin{array}{l}\text { Woman's actual attitude and } \\
\text { satisfaction }\end{array}$} \\
\hline & AAPPI $^{2}$ & $\mathrm{SAP}^{3}$ & $\mathrm{PAPI}^{4}$ & Satisfaction \\
\hline $\begin{array}{l}\text { Man's satisfaction at } \\
\text { prosthesis-assisted sexuality }\end{array}$ & $-0.51^{\star \star}$ & $0.50^{\star \star \star}$ & NS & NS \\
\hline Man's feeling of shame & $0.39 \star$ & NS (tendency) & NS & $-0.44^{\star}$ \\
\hline $\mathrm{API}^{1}$ & $0.58^{\star}$ & $-0.42^{\star \star}$ & NS & NS \\
\hline Man's satisfaction & $-0.44^{\star}$ & & & \\
\hline concerning the penile size & & $0.43^{\star \star}$ & NS & NS \\
\hline $\mathrm{AAPPI}^{2}$ & & & NS & NS \\
\hline $\mathrm{SAP}^{3}$ & & & NS & NS \\
\hline
\end{tabular}

1. API: Man's Attitude towards Penile Implant

2. AAPPI: Attitude Attributed to the Partner towards Penile Implant

3. SAP: Satisfaction Attributed to the Partner

4. PAPI: Partner's Attitude towards Penile Implant

${ }^{\star} p<0.05 ;{ }^{\star \star} p<0.01$.

\section{Discussion}

Functional reasons for dissatisfaction

A previous study by our team (Kempeneers et al., 1992) indicated that part of the dissatisfaction derived from technical and functional problems such as difficulties in manipulating the prosthetic device, unwanted deflations, lack of penis sensitivity, pain and uncomfortable sensations while urinating or in case of contact with certain pieces of cloth. That study also found negative relationships between the follow-up duration and the frequency and/or the subjective importance of these problems: they mostly occurred during the first months following the implantation and decreased with time 
through a habituation process. In the present study, the lack of penile sensitivity is the only functional problem significantly related to the satisfaction rate. This discrepancy could be explained by a difference in the follow-up durations: in the previous study, the average follow-up duration was 22 months as against 52 months in the present one. Facing this, the ratio of subjects who never meet functional difficulties has increased from $47-60.5 \%$ for the manipulation and inflation/deflation problems and from $64-79.5 \%$ for the uncomfortable sensations. Among the patients who report such difficulties at least sometimes, the ratio of those who consider them not important at all or only few important (scores 1 or 2 on 5 -point scales) has increased from $66-93.3 \%$. The ratio of patients who exhibit a lack of penile sensitivity is comparable in both studies (41.7-48.7\%), but the ratio of those who consider it not or few annoying (scores 1 or 2 on 5 -point scales) has increased from $55.6-66.7 \%$. These observations confirm that functional problems are liable to spontaneous fading and gradual adaptation. A longer average postoperative period probably explains why the functional difficulties have, in the present study, a smaller impact on satisfaction levels: except for the lack of sensitivity, most of the patients are out of the 'critical period'. Finally, this could also explain why, in this study, the follow-up duration remains a variable without effect on satisfaction rates.

\section{Psychological reasons for dissatisfaction}

Apart from its link with diminished penile sensitivity, the dissatisfaction appears to be mostly determined by psychological variables.

The results of the present study show significant correlations between the dissatisfaction level and four attitudinal parameters, which reveal the presence of a social representation of virility that makes the adjustment to prosthetic sexuality rather precarious:

(1) Low satisfaction rates are linked to high values at API scale. The dissatisfaction related to prosthesis-assisted sexuality correlates with a negative attitude towards the penile implant, which refers to an impression of self-erotic value damaged by concepts of assistance, lack of spontaneity and lack of naturalness associated with the prosthesis.

(2) The dissatisfaction also correlates with a feeling of shame derived from having a penile prosthesis.

(3) The patients' dissatisfaction is inversely proportional to their tendency to consider their prosthesis as a sexual handicap.

(4) The dissatisfaction concerning sexual-assisted sexuality is also linked to the dissatisfaction about the erectile size after implantation. Since this parameter is classed as a psychological variable rather than as a functional one, it is important to underline that (1) the complaints related to a penile shortening are not related to the surgeons' opinion concerning the actual penile reduction. In other words, some patients who exhibit an substantial penile shortening after surgery do not complain, while other patients with a negligible shortening complain a lot; and (2) that the complaints about a shortening do 
not correlate with the partners' sexual satisfaction; obviously, the partners' satisfaction does not depend on a criterion of erectile size. Therefore, the disappointment about penis length is not related to an objective shortening and not related to a functional problem in the couple due to a shortened penis. It is more reliable to think that men who express such complaints are principally sensitive to the symbolic dimension of the penis size.

Table $\mathrm{V}$ indicates that these four parameters which alter the satisfaction with prosthesis-assisted sexuality are strongly interrelated. They express the same complex: a male self-image injured by a specific social representation of sexuality which associates the male erotic value to criteria of erectile length, non-assistance, spontaneity and naturalness.

\section{Maladaptive representation of sexuality, intervention and detection}

The prosthetic erections are often reduced as compared to natural ones; they are always less 'spontaneous' and less 'natural'. When a representation of erotic value based on criteria of erectile length, spontaneity and naturalness is present in a subject's mind, it decreases his ability to be satisfied by prosthetic sexuality. Although his erection is made functional again, his feeling of impotence does not entirely disappear.

Complaints related to a penile shortening after implantation are frequently reported in the literature (Candela \& Hellstrom, 1996; Kempeneers et al., 1992, 1994a; Montorsi et al., 2000). In order to manage this problem, surgeons can use several techniques (e.g. cutting of the ligator) and materials (e.g. Ulterx cylinders) enabling a further lengthening of the penis. But independently of their results still under discussion (Kempeneers et al., 2001; Wilson et al., 1996), these options remain insufficient since they do not salve the other problematic aspects of the male image associated with the question of the penile size. Even if medical techniques allowed prosthetic erections with the same size as natural ones, these erections would anyway remain 'assisted', 'unnatural' and 'unspontaneous'. When a shortened erection is a problem for a patient, this is mainly related to a complex sexual representation in which the feeling of lost virility is the core symptom (Kempeneers et al., 2001).

The limits of the prosthetic surgery underline the usefulness of a complementary psychosexological approach in order to modify some patients' representations and to dissociate their feeling of virility from criteria such as erectile length, non-assistance, naturalness and spontaneity.

In this respect, it would be interesting to identify during the preoperative period patients in which adaptation to penile implant will be ineffective. The API scale might be useful here. This scale easily quantifies the presence of a maladaptive sexual representation in candidates to a penile implant, and it can offer an indication on their ability to adapt to prosthesis-assisted sexuality. This would be a basis for an indication of psychosexual counselling. Kempeneers et al. (2001) suggest that an API score superior or equal to 28 could be considered as the cut-off indicating a high probability of maladjustment to prosthetic sexuality. However, this estimation is based on data 
collected after prosthesis implantation. The prognostic value of individual preoperative API scores could be assessed by studies including API preoperative scores and satisfaction after implantation. Such studies will permit to be sure that an API high score is really a predictor rather than simple correlate of maladjustment.

\section{Maladaptive representation and satisfaction in the couple}

Several lines of evidence suggest that a psychosexological approach would be indicated not only for the man but also for the couple:

(1) Men perceiving themselves as diminished lovers because of their prosthesis also tend to attribute erroneously to their partner a negative attitude towards the penile implant and less satisfaction. The present results show that elements denoting a maladaptive representation of male erotic value involve in men a tendency to attribute to their partner the same reservations about the penile implant. The more the man has a negative attitude towards his prosthesis, the more he supposes that his partner has the same negative attitude and is unsatisfied. However, there is no correlation between what the man assumes and his partner's actual attitude and satisfaction concerning prosthetic sexuality. More specifically, men who exhibit a very negative perception of prosthetic sexuality (API $\geqslant 28$ ) systematically overestimate the negative attitude of the partner and underestimate her sexual satisfaction [1]. Moreover, the partner's satisfaction seems not affected by the considerations related to the penile size which debase some men's male self-image and lead them to feel diminished.

In consequence, patients whose satisfaction is diminished by a representation of erotic value based on erectile volume, naturalness and spontaneity criteria exhibit an attribution bias consisting in projecting improperly in their partner's mind their own sensitivity related the penile implant.

Moreover, this attribution bias may be accentuated by a lack of communication observed among their partners since an inversed correlation is found between men's satisfaction with prosthesis-assisted sexuality and women's score at the SIQ-F2 (lack of communication).

In the sum, men's dissatisfaction with prosthetic sexuality does not refer to the feelings and opinions of the partner. On the other hand, man's dissatisfaction depends on what he assumes to be his partner's opinion, but such an assumption is finally nothing else than the projection of his own stereotypes. Therefore, in order to help men to fit better with prosthesisassisted sexuality, it would be suitable to improve the communication within the couple and, through a kind of 'reality test', to confront men's maladaptive erotic representations to their partner's actual opinion on prosthetic sexuality.

(2) The partner's attitude and satisfaction concerning the penile implant is generally better than assumed by male patients with a maladaptive representation of prosthesis-assisted sexuality. Nevertheless, the results suggest a possible indirect impact of men's maladaptive representation on women's satisfaction. 
Women's satisfaction decreases according to the fact that men feel ashamed to have a prosthesis and that they are intolerant to sexual frustrations (e.g. frustrations related to a feeling of sexual inadequacy-SIQ-F4). This may result from the following process: although their partner is not sensible to the same representation than them, some men are convinced they are diminished lovers; in consequence they are frustrated in erotic situations and, mostly if they are intolerant to frustrations, they probably tend to express their emotion in a behaviour inadequate to their partner's sexual expectations, inducing a decrease of her sexual satisfaction. Therefore, an intervention focused on the man's representation would probably result in an indirect improvement of the woman's satisfaction.

(3) If it does not really reflect men's opinions and attributions concerning the prosthetic sexuality, women's satisfaction may nevertheless be diminished by their own negative perception of penile implant. This is supported by a negative correlation between their attitude towards penile implant (PAPI) and their satisfaction at prosthesis-assisted sexuality.

Even if she is not the direct recipient of the prosthesis, the woman participates in its use. In this respect, her satisfaction must also be taken into account, and in consequence her own representation of prosthesis-assisted sexuality should also be managed in order to improve her satisfaction.

\section{The part of maladaptive representation in refusing the implantation}

In a previous study, Kempeneers et al. (1994b) questioned why some patients with a severe erectile disorder refused a penile implantation although their sexuality was unsatisfactory. A sample of 17 of these patients was studied by a mailed questionnaire. The 'artificial' aspect of the sexual-assisted sexuality appeared to be the second reason for refusal ( $46 \%$ ), the cost of the device being the first one $(61.5 \%)$. For almost half of these patients, the lack of naturalness associated with the prosthesis led them to consider this solution as worse than nothing. Since the results of the present study suggest that the negative awareness of the artificial connotation of the implant is part of a more general representation, we can argue that the maladaptive representation associating the male erotic value with natural, spontaneous, nonassisted and large erections is probably a factor which conducts some patients to refuse a penile prosthesis. Insofar as their sexuality remains unsatisfactory, a psychosexual intervention would be indicated to make the prosthetic solution more attractive or to help them to feel better in their sexuality without either prosthesis or erection.

\section{Conclusions}

While a penile prosthesis may cure an erectile disorder, it may be insufficient to alleviate a feeling of impotence. Beyond the question of having an erection or not, remains the question of 'how' to achieve an erection. 
Women's satisfaction decreases according to the fact that men feel ashamed to have a prosthesis and that they are intolerant to sexual frustrations (e.g. frustrations related to a feeling of sexual inadequacy-SIQ-F4). This may result from the following process: although their partner is not sensible to the same representation than them, some men are convinced they are diminished lovers; in consequence they are frustrated in erotic situations and, mostly if they are intolerant to frustrations, they probably tend to express their emotion in a behaviour inadequate to their partner's sexual expectations, inducing a decrease of her sexual satisfaction. Therefore, an intervention focused on the man's representation would probably result in an indirect improvement of the woman's satisfaction.

(3) If it does not really reflect men's opinions and attributions concerning the prosthetic sexuality, women's satisfaction may nevertheless be diminished by their own negative perception of penile implant. This is supported by a negative correlation between their attitude towards penile implant (PAPI) and their satisfaction at prosthesis-assisted sexuality.

Even if she is not the direct recipient of the prosthesis, the woman participates in its use. In this respect, her satisfaction must also be taken into account, and in consequence her own representation of prosthesis-assisted sexuality should also be managed in order to improve her satisfaction.

\section{The part of maladaptive representation in refusing the implantation}

In a previous study, Kempeneers et al. (1994b) questioned why some patients with a severe erectile disorder refused a penile implantation although their sexuality was unsatisfactory. A sample of 17 of these patients was studied by a mailed questionnaire. The 'artificial' aspect of the sexual-assisted sexuality appeared to be the second reason for refusal ( $46 \%$ ), the cost of the device being the first one $(61.5 \%)$. For almost half of these patients, the lack of naturalness associated with the prosthesis led them to consider this solution as worse than nothing. Since the results of the present study suggest that the negative awareness of the artificial connotation of the implant is part of a more general representation, we can argue that the maladaptive representation associating the male erotic value with natural, spontaneous, nonassisted and large erections is probably a factor which conducts some patients to refuse a penile prosthesis. Insofar as their sexuality remains unsatisfactory, a psychosexual intervention would be indicated to make the prosthetic solution more attractive or to help them to feel better in their sexuality without either prosthesis or erection.

\section{Conclusions}

While a penile prosthesis may cure an erectile disorder, it may be insufficient to alleviate a feeling of impotence. Beyond the question of having an erection or not, remains the question of 'how' to achieve an erection. 
The patients who are less satisfied with their penile implant are those who show a representation of virility that associates the male erotic value to criteria of large, natural, spontaneous and non-assisted erections. Since the penile prosthesis does not enable them to meet all these criteria, a feeling of impotence persists and they regard themselves as diminished lovers.

Therefore, a psychosexual intervention focused on such a maladaptive representation would be relevant in order to help them to feel better in prosthesis-assisted sexuality. The API scale might permit to identify these patients preoperatively. If possible, the psychosexual counselling would have to consider the couple rather than the male patient alone since (1) the man with a maladaptive representation attributes improperly his own reservation and dissatisfaction to his partner, (2) the partner's satisfaction may be altered by her own maladaptive representation of sexuality and (3) womens' difficulties of communication and mens' intolerance to sexual frustrations may contribute to aggravate the problem. Finally, this maladaptive representation probably leads some patients with severe erectile disorder to refuse the prosthetic solution and to resign themselves to a sexual decline.

\section{Notes}

1. In this sub-group (valid $n=5$ ), average AAPPI and average satisfaction attributed to the partner are respectively 30.9 and 3.8 as against 17.3 and 4.6 respectively for average PAPI and average partner's actual satisfaction. However these differences are not statistically significant due to the weakness of the valid number.

\section{References}

Anafarta, K., Yaman, O. \& Aydos, K. (1998). Clinical experience with Dynaflex penile prosthesis in 120 patients. $52(6), 1098-1100$.

Candela, J.V. \& Hellestrom, W.J. (1996). Three-piece inflatable penile prosthesis implantation: a comparison of the penoscrotal and infrabubic surgical approaches. Fournal of the Louisiana State Medical Society, 148(7), 296-301.

COLLINS, G.F. \& KINDER, B.N. (1984). Adjustment following surgical implantation of a penile prosthesis: a critical overview. Fournal of Sex and Marital Therapy, 10, 255-271.

Goldstein, I., Bertero, E.B., Kaufman, J.M., Witten, F.R., Hubbard, J.G., Fitch, W.P., et al. (1993). Early experience with the first pre-connected three-piece inflatable penile prosthesis: the Mentor Alpha-1. 150(6), 1814-1818.

HOLlowAY, F.B. \& FARAH, R.N. (1997). Intermediate term assessment of the reliability, function and patient satisfaction with AMS 700 Ultrex penile prosthesis. Fournal of Urology, 157(5), $1687-1691$.

KeMPENEERS, P., ANDrianNe, R. \& MORMONT, C. (1992). Evaluation par questionnaire des inconvénients liés aux prothèses péniennes chez 25 implantés [Penile prosthesis: problems of use in a sample of 25 recipients]. Andrologie, 2, 130-133.

Kempeneers, P., Andrianne, R. \& Mormont, C. (1994a). La prothèse pénienne: contrariétés d'une virilité artificielle [Penile prosthesis: the frustrations of artificial virility]. 3(13), 26-30.

Kempeneers, P., ANDrianne, R. \& MORMONT, C. (1994b). La prothèse pénienne dans le traitement de l'impuissance: la décision du patient [Penile prosthesis in the treatment of impotence: patient's decision]. Cahiers de Sexologie Clinique, 20(124), 31-36.

Kempeneers, P., Andrianne, R., Mormont, C., Jeanmart, F. \& Blochousse, L. (2001). Prothèse pénienne: taille du pénis implanté et dimensions de la virilité [Penile prosthesis: size of the implanted penis and dimensions of virility]. Cahiers de Sexologie Clinique, 27(149), 18-27. 
Kempeneers, P., Louwette, S., Mormont, C. \& Doudali, P. (2000). Adaptation et validation française du Sexual Irrationality Questionnaire (SIQ) de McCormick et Jordan [French adaptation and validation of McCormick and Jordan's Sexual Irrationality Questionnaire (SIQ)]. Revue Francophone de Clinique Comportementale et Cognitive, 5(3), 5-18.

Kupeli, S., Aydos, K. \& BudAK, M. (1999). Penile implants in erectile impotence. The importance of clinical experience on outcome. European fournal of Urology, 36(2), 129-135.

LIKerT, R. (1932). A technique for the measurement of attitudes. Archives of Psychology, 140, 1-55.

McCormick, N.B. \& Jordan, T.J. (1986). Thoughts that destroy intimacy: irrational beliefs about relationships and sexuality. In W. DRYDEN \& P. TOWER (Eds), Rational-Emotive Therapy: recent developments in theory and practice. Bristol: Institute for RET.

MCLAREN, R.H. \& BARRETT, D.M. (1992). Patient and partner satisfaction with the AMS 700 penile prosthesis. Fournal of Urology, 147(1), 62-65.

Montorsi, F., Rigatti, P., Carmignani, G., Corbu, C., Campo, B., Ordesi, G., et al. (2000). AMS three-piece inflatable implants for erectile dysfunction: a long-term multi-institutional study in 200 consecutive patients. European fournal of Urology, 37(1), 50-55.

Moscovici, S. (1981). On social representations. In J.P. Forgas (Ed.), Social cognition: perspectives on everyday understanding. London: Academic Press.

MoscovicI, S. (1988). Notes towards a description of social representations. European fournal of Social Psychology, 18, 211-250.

MuLCAHY, J.J. (2000). Surgical management of penile prosthesis complications. International fournal of Impotence Research, 12(4), 108-111.

Porena, M., Mearini, L., Mearini, E., Marzi, M. \& Zucchi, A. (1999). Penile prosthesis implantation and couple's satisfaction. Urologia Internationalis, 63(3), 185-187.

SCHOVER, L.R. (1989). Sex therapy for penile prosthesis recipient. 16, 91-98.

SCHOVER, L.R. \& Von EschenBACH, A.C. (1985). Sex therapy and the penile prosthesis: a synthesis. 11, $57-66$.

Tefilli, M.V., Duboce, F., Rajpurkar, A., Gheiler, E.L., Tiguert, R., Barton, C., et al. (1998). Assessment of psychosexual adjustment after insertion of inflatable penile prosthesis. Urology, 52(6), 1106-1112.

Wilson, S.K., Cleves, M.A. \& DelK, J.R. (1996). Ultrex cylinders: problems with uncontrolled lengthening. Fournal of Urology, 155(1), 135-137.

\section{Contributors}

Philippe Kempeneers, Psychologist, Sexologist and Psychotherapist

Robert ANDRIANNe, Urologist, Professor of Sexual Medicine

Christian Mormont, Psychologist, Professor of Clinical Psychology

(All are members of the Société des Sexologues Universitaires de Belgique; Belgian Association of Sexology) 